\title{
A Argentina Inflamada De Vogue Paris
}

Daniela Novelli

Doutora, Universidade do Estado de Santa Catarina/ daniela.novelli@udesc.br Orcid: 0000-0001-6981-8933/ lattes

Enviado 13/11/2018 / Aceito 21/02/2019 


\title{
A Argentina Inflamada De Vogue Paris
}

\begin{abstract}
RESUMO
A edição francesa do periódico Vogue publicada em fevereiro de 2006, inteiramente consagrada à Argentina, incluindo o editorial de moda Tango des Passions, revelou simbolicamente a aproximação dos laços de transmissão cultural entre a Europa e a Argentina, a partir de uma construção discursiva baseada na philia - uma das atitudes fundamentais que regem a representação do Outro no diálogo intercultural. Realizado por Carine Roitfeld e fotografado por Mario Testino, foi interpretado à luz da teoria de Daniel-Henri Pageaux, que colocou a valorização da "cultura olhada" no centro de uma tensão permanente, cujo espelho reflete um "Eu-narrador" explicitamente duplicado, como um duplo corpo [branco] da alta moda europeia. Seja pelo "temperamento borbulhante", pelo "teatro da moda", pelo "excesso latino" ou ainda pela "dor estonteante" atribuídos à imagem da Argentina e à sua própria imagem, Vogue Paris estabelece um diálogo intercultural ambíguo e inflamado.
\end{abstract}

Palavras-chave: Vogue Paris; Argentina; imagem do Outro. 


\title{
The Inflamed Argentina Of Vogue Paris
}

\begin{abstract}
The French edition of the Vogue published in February 2006, entirely devoted to Argentina, including the fashion editorial Tango des Passions, symbolically revealed the approximation of cultural transmission links between Europe and Argentina, based on a discursive construction based on the philia - one of the fundamental attitudes that govern the representation of the Other in intercultural dialogue. Carine Roitfeld, photographed by Mario Testino, was interpreted in the light of Daniel-Henri Pageaux's theory, which placed the appreciation of the "culture looked" at the center of a permanent tension whose mirror reflects an explicitly duplicated "I-narrator" as a double body [white] of European high fashion. Vogue Paris establishes an ambiguous and inflamed intercultural dialogue, whether through "bubbling temperament", "fashion theater", "Latin excess" or "stunning pain" attributed to the image of Argentina and its own image.
\end{abstract}

Keywords: Vogue Paris; Argentina; the Other's image. 


\section{INTRODUÇÃO}

Em fevereiro de 2006, o periódico Vogue Paris homenageia a Argentina ${ }^{1}$. Segundo sua redatora-chefe, trata-se de um país de temperamento borbulhante, "elo quase sanguíneo com a Europa misturado à excessividade latina e vertiginosa capital sofrimento" (Roitfeld, 2006a, p.72). Primeiramente, deve-se levar em conta que toda adjetificação permite por si mesma a compreensão de certos procedimentos de qualificação, conforme salienta Daniel-Henri Pageaux (2007) e, neste caso, foi possível perceber que ela é bem o resultado de todo um trabalho simbólico sobre a imagem da Argentina, produzido pela edição francesa ${ }^{2}$. Moda, cinema, culinária e literatura se entrelaçam para seduzir, inflamar e positivar o diálogo intercultural em jogo.

A philia é uma das atitudes fundamentais que regem a representação do Outro. É quando "a verdade cultural estrangeira é tomada por positiva, ganhando seu lugar em uma cultura que a olha [regardante], que por sua vez é uma cultura acolhedora, tida igualmente por positiva" (PAGEAUX, 2007, p. 48, tradução nossa). As palavras escolhidas pelo periódico na abertura da edição revelam que as duas culturas são percebidas como complementares e, então, uma troca já é possível aos olhos de Vogue. Entretanto, identificar os marcadores de reconhecimento do Outro enquanto "Outro" não é sempre evidente, nem mesmo suficiente para garantir a vontade permanente de um diálogo intercultural privilegiado - pois um simples ato de boa vontade pode ser explicado pela preocupação em reestabelecer certo equilíbrio rompido por fobias ou manias. Existem relações hierarquizadas que se

\footnotetext{
${ }^{1}$ Trata-se de edição analisada em pesquisa pós-doutoral realizada na Université Paris-Sorbonne, com a bolsa de pesquisa CAPES BEX 6682/14-6 (Brasil).

${ }^{2}$ Vogue Paris numéro 864 Février 2006. Devido à não permissão dos direitos autorais de uso das imagens do editorial analisado, estas foram suprimidas deste artigo. Esta edição encontra-se disponível para consulta no acervo da Bibliothèque des Arts Décoratifs com o código JP 168.
} 
afirmam sobre o corpo do Outro, bem como em diversas manifestações de sua cultura e de seu sistema de valores.

No século $X X$, a América latina funciona como um laboratório no qual é fácil, de um lado, ver esmigalhar o monopólio de uma Europa 'elaboradora' de modelos; e de outro, constatar, em certos casos, a inversão do sentido de transferência. Aliás, isso não significa que Europa e América latina não participam ainda de um mesmo conjunto cultural supraregional (ROLLAND, 2011 , p. 83 , tradução nossa).

\section{A ARGENTINA "ABRAÇADA": O OUTRO DO MESMO?}

O editorial de moda intitulado Tango des passions foi produzido por Carine Roitfeld e fotografado por Mario Testino. Mariacarla Boscono e Patricia Schmid, as manequins escolhidas para o shooting, fizeram também a capa da edição, vestidas em preto e vermelho. Já nas duas primeiras páginas, é possível captar quase instintivamente a atmosfera do "teatro da moda" oferecido por Buenos Aires e todas as suas forças vivas: ela se apresenta ao mesmo tempo inflamada, audaciosa, sensual, autêntica e elegante.

O periódico procura trazer a valorização positiva e duplamente reconhecida da "mais parisiense das cidades argentinas" (ROITFELD, 2006b, p.182), jogando com a simbologia do "duplo", a partir da qual toda uma sequência é programada, na medida em que imagens veiculadas são dispostas de modo suficientemente estável sob a ótica da cultura que olha [regardante] (PAGEAUX, 2007).

Juciane Cavalheiro e Rosana Fonseca (2011) analisaram contos literários do célebre escritor argentino Jorge Luis Borges, dentre eles L'Autre, le Même e, segundo as pesquisadoras, ser "o Outro do mesmo" implica em um "paradoxo interior e exterior, ao mesmo tempo contraditório e complementar, o que provoca ao 'eu' original reações emocionais extremas, como a fascinação e a aversão ao seu 'outro'. Assim, a valorização da cultura olhada [regardée] em 
Vogue se coloca no centro de uma tensão permanente, cujo espelho intercultural onde franceses e argentinos se olham reflete um "Eu-narrador" explicitamente duplicado, um duplo corpo [branco] da alta moda europeia.

Em seguida, é possível encontrar uma forte semelhança entre as duas manequins: elas possuem os mesmos cabelos curtos (exceto que estão em cores radicalmente opostas); elas usam os mesmos modelos de sandálias (prateadas e de salto alto), os mesmos elementos enrolados em volta de seus braços e parecem estar vestidas pelo mesmo modelo de roupa preta. Mas este jogo de dualidades está repleto de pequenas diferenças, reveladas pela imagem e pelo texto de ancoragem: a jovem modelo de cabelo loiro usa um top e uma saia de couro ligeiramente évasé e brillante, ao passo que a jovem modelo de cabelo preto usa um vestido reto e opaco. Além disso, as peças pretas são assinadas por Yohji Yamamotto (criador japonês de estilo minimalista), que foi protagonista do movimento desconstrucionista e cujos relatos inspiraram o cineasta alemão Wim Wenders a tratar de moda no filme "Identidade de nós mesmos" em 1989.

Escolhas que parecem muito apropriadas à temática do teatro da moda, pois toda a sutileza desconstruída e andrógina se mistura a uma dose bastante elevada de sensualidade e desejo. A manequim italiana Boscono possui os cabelos em loiro platina, cor das atrizes hollywoodianas dos anos 1930, que se tornaram verdadeiros símbolos sexuais, como Jean Harlow; ela tem de fato uma constituição física associada ao corpo andrógino, com uma pele de opala, um estilo rock chic (onde o preto predomina). Em 2006, mesmo ano desta produção de Vogue, ela se aventurava nas artes dramáticas. É a moda à la folie (VOGUE PARIS, 2006, p. 181) que aproxima e/ou enfrenta. Aliás, o escritor argentino Alan Pauls a testemunhou na rubrica "Magazine": 
[...] em Buenos Aires, [...] se é confrontado com a sutileza de uma oscilação, de um vai-e-vem entre o familiar e o estrangeiro, o conhecido e o desconhecido, o mesmo do outro. Mesmo se os elos definitivos a relacionem com a Europa (entre outros, uma população essencialmente de origem italiana, espanhola ou judia), Buenos Aires não é uma cidade europeia: ela é quase uma. É justamente neste quase que habita seu charme" (PAULS, 2006, p. 211, tradução nossa).

O discurso midiático produzido por Vogue sintoniza parcialmente com o que Marcel Peyrouton escreveu nos anos 1950: "Buenos Aires, sob a poeira de uma evolução, ganha forma de uma vila americana e, entretanto, a alma é latina, nobremente, e mais ainda: francesa e mesmo parisiense" (1950, apud ROLLAND, 2000, p.103, tradução nossa). É preciso salientar que este francês conheceu a Argentina nos anos 1930 e mais tarde ele foi embaixador neste país por duas vezes (1936-1940 e 1941-1942), bem como ministro de Vichy neste intervalo. Na mesma onda, André Siegfried afirmou que "um Francês, na América latina, nunca é completamente estrangeiro" (apud ROLLAND, 2000, p.93), na ocasião do convite do Instituto da Universidade de Paris, em 1937.

Rita Segato (apud FRIERA, 2012, p. 12) nos lembra que o mito do crisol de razas quer a todo custo assegurar a ideia de que o argentino é uma mistura de nacionalidades europeias. Esta espécie de "ausência de alteridade" entre Buenos Aires e Paris está contudo limitada por um lado às elites latinoamericanas e europeias [...] e de outro a uma percepção redutora, mas conforme afirma Denis Rolland (2000, p. 94, tradução nossa) é "quase sempre involuntária, vindo mais duravelmente das elites francesas do que das gerações sucessivas das elites latino-americanas".

Como os "dois Borges" do conto de Borges - um homem fragilizado pela solidão e pela cegueira e um outro homem bem mais jovem inventado talvez pelo próprio autor (CAVALHEIRO e FONSECA, 2010) - os gestos diferentes dos dois personagens de Vogue parecem revelar na cena uma 
ambiguidade implicada neste espelhamento: o corpo da loira (do Eu-narrador) é um corpo ativo, que tem vontade de abraçar o corpo do Outro ou dele mesmo (nesta perspectiva), por sua vez um corpo passivo. Os protagonistas de Vogue, como muitos personagens criados por Borges, parecem "não possuir prazer em encontrar com eles próprios, pois quando chegam a fazê-lo estão em uma ambientação onírica ou claramente no ponto de morrer" (CAVALHEIRO e FONSECA, 2011). De fato, suas relações parecem liberar algo de absolutamente passional e obscuro, potencializado por um tipo de "emoção perturbadora entre ficção e realidade" (Rachline, 2006b, p. 265, tradução nossa).

A linguagem visual de Vogue Paris evidencia um diálogo entre o Eu-narrador e o Outro, em cenas repletas de componentes simbólicos (CAVALHEIRO e FONSECA, 2011), dentre eles o cavalo. A história da equitação - seja ela de corte, militar ou esportiva - e mesmo o uso deste animal, remetem ao universo da caça, da guerra, do transporte e da tradição. O cavalo que aparece em Tango des passions tem porte elegante, reconhecido como de sangue, rápido, viril, inteligente e manejável. Na imagem, metade de seu corpo está escondida por trás das manequins, mas sua aparição é surpreendente, uma vez que encontra-se molhado de água e sabão; seu olhar é direcionado às duas jovens mulheres, reforçando a importância do duplo na cena.

Ao lado do animal, há um jovem modelo branco e forte com tronco à mostra, vestindo uma calça branca Levi's e botas longas de equitação; seu olhar, lançado para fora da cena, é o mesmo olhar indefinível da modelo brasileira Jeisa, no editorial de outra edição francesa de Vogue, dedicada ao Brasil. Entretanto, se a calça branca da capoeira encontrada nesta última representava uma herança cultural africana, agora a calça branca Levi's aparecia como um dos símbolos 
associados à herança cultural do jogo de polo - esporte da realeza por excelência.

Portanto, há uma aproximação dos elos de transmissão cultural entre a Europa e a Argentina, por meio da manipulação de signos do universo das elites sociais que, na Argentina do século $X X$, apresentava uma visível obsessão por corridas de cavalos e certa preferência por jogos de azar (BETHELL, 1992). Além disso, o bairro chique de Palermo preserva uma aura glamorosa sobretudo após o ano 2000, passando a abrigar diversos produtores de cinema e televisão e se tornando reconhecida como "Palermo Hollywood". Enfim, tudo isso convida a uma melhor compreensão dos "estados de dependência cultural que fizeram da Françe [Paris de Francia!] um modelo ativo para a América do Sul" (PAGEAUX, 2007, p. 53, tradução nossa).

Nenhum outro país latino é tão bem versado no polo como a Argentina, jogo de corte trazido ao país por imigrantes ingleses ainda no final do século XIX. Buenos Aires acolhe um campeonato de polo chamado Open de Palermo desde o ano de 1893, suscitando ao longo do tempo a mesma atenção dada ao futebol. $\mathrm{O}$ esporte fez sua primeira aparição olímpica na cidade de Paris, no início do século XX.

Pierre-Marie Taillepied [le Comte de Bondy], homem político engajado com o clube argentino, descreveu com bastante entusiasmo na revista Le Miroir du Monde: "Como Espetáculo, [o Polo] oferece um ardente emaranhamento de linhas quebradas, que agrada por seu contraste com as linhas curvas calmas e eternas da decoração". Tal discurso do início do século XX já revelava uma percepção estética muito refinada desta ambiguidade formal, que tornava o polo um esporte atraente tanto pela visão oferecida quanto pela atmosfera criada em torno dele - fórmula retomada por Vogue Paris em 2006. 


\section{O ASADO COMO EXAGERO LATINO}

No início do século $X X$, a Argentina alcançou o posto de importante exportadora mundial de cereais e carne bovina, sendo ainda a terceira potência em exportação de gados e cavalos vivos. Vogue Paris faz desta vez referência a uma das tradições culturais mais significativas do país: o asado [churrasco]. Quase sempre associado às paisagens dos pampas [pradarias] e à mítica figura do gaucho (espécie de cowboy da Argentina), esta "arte culinária sagrada" é geralmente preparada no domingo e consumida em família ou entre amigos, mantendo viva uma "vocação" pecuária associada historicamente à imagem do país, assim como do Uruguai e do sul do Brasil. O asado é portanto uma tradição cultural mantida pelos habitantes de uma parte considerável da América do Sul, onde a preparação e o consumo da carne implicam diversos hábitos e relações sociais. A Argentina é a maior consumidora de carne bovina do mundo.

A segunda imagem analisada no editorial francês mostra a figura de um assador, a pessoa que se ocupa do preparo e cozimento da carne, que aparece à esquerda vestindo uma calça jeans azul, camisa branca e um longo avental branco amarrado em torno da cintura. Bem na sua frente, uma enorme grelha repleta de carne, com carvão embaixo. Ao fundo, frondosas árvores com folhas verdes mais à esquerda da imagem e um céu acinzentado à direita, com mais algumas árvores menos luminosas. Pode-se dizer que a revista procura encenar toda uma eficácia simbólica desta tradição popular da culinária argentina e sul-americana, cujo "Eu-narrador" duplicado é mais uma vez o resultado de um diálogo paradoxal, ao mesmo tempo contraditório e complementar.

As mesmas manequins, Boscono e Schmid são valorizadas pela luminosidade e por seus vestidos volumosos de musseline de seda estampado com flores japonesas, assinados pela marca Comme des Garçons - da criada por Rei 
Kawakubo, cujo estilo questiona a normalidade de conceitos estéticos estabelecidos). Assim, roupas inacabadas, silhuetas desestruturadas e volumes desproporcionais podem materializar o desejo de preservar certo espírito incorrigível ou uma insolência libertária, comum entre as duas culturas (argentina e francesa), levado talvez pela cristalização dos princípios revolucionários de 1789 - que, segundo Denis Rolland (2000, p.93) constituíram a "era de ouro" de um modelo dominante republicano na América latina das três primeiras décadas do século $X X$.

É importante salientar que não se trata agora de uma tradição cultural ligada às heranças das elites modernas inglesas ou francesas, como foi o caso do jogo de polo. Está em jogo uma tradição popular hispânico-americana (asado), que se torna um catalisador conceitual da representação do Outro; apesar da incerteza de sua origem, o churrasco é diretamente associado às regiões pastorais da Espanha, sendo aliás um símbolo da gastronomia de Castilla, onde povos nômades do século XVIII degustavam a carne de cordeiro. Seu preparo exigia apenas um forno e um prato de argila. Na Argentina, a carne de boi é preparada majoritariamente por homens, que assam na brasa de carvão vegetal enormes pedaços dispostos sobre uma grelha. Os gauchos tornaram-se verdadeiros especialistas na elaboração do asado a la cruz, quando um grande utensílio de ferro é enterrado no chão e envolto por fogo de madeira de fazenda.

O exagero latino associado à alta moda vendida em Vogue Paris passa pela carne e pela roupa, ou seja, os dois maiores savoir-faires da Argentina e da França. Esta imagem representativa da cultura olhada [regardée] se inscreve no centro de um discurso que pretende incarnar o espírito de vanguarda e de excelência em criatividade. Kate Best (2008, p. 7, tradução nossa) escreveu no Web Journal of Media French Studies que "o discurso e a criatividade da nação 
Francesa, para quem a moda funciona como um signo, foram cada vez mais reificados por um paradigma cultural introspectivo e burguês".

Na rúbrica En Vogue desta edição de 2006, a revista fala de um retorno ao glamour latino dos anos 1950 (POIBLANC, 2006), que traz um toque de audácia e excesso, bem como de "sex-appeal ao mesmo tempo cru e civilizado" (PAULS, 2006, p. 211, tradução nossa). Há, portanto, nesta imagem do churrasco mais um paradoxo comparável à capital argentina, vista pelo escritor Pauls (2006, p. 211, tradução nossa) como sendo "ao mesmo tempo moderna e periférica, global e ainda um pouco provincial". A simbologia do duplo joga aqui entre o estranho e o familiar, sem os considerar necessariamente opostos. O corpo do "Outro do mesmo" é posicionado mais para o meio da cena, direcionando-se para o lugar desta tradição supostamente pouco apreciada, cujo olhar libera curiosidade e aversão; seu duplo, o "Eu-narrador" mantém o olhar em direção à câmera (ou ao observador) mas retém suavemente $\mathrm{o}$ primeiro, pois sabe que "o exotismo implica certo contato e justaposição de mundos" (LEITÃO, 2007, p. 273).

Porém, a ausência de interação entre o "Eu-narrador" (incluindo seu duplo) e o Outro (o assador) na imagem analisada pode indicar a preservação da diferença, típica da ambivalência pós-moderna, que arrisca ignorar a alteridade e a cultura do Outro.

\section{O SOFRIMENTO EM FRONTEIRAS PRAZEROSAS}

Na rúbrica Magazine, Vogue afirma que a ditadura argentina se tornou uma "lembrança que não acaba de se desdobrar no presente, ferida viva, mesmo nas gerações que não a viveram" (RACHLINE, 2006b, p. 264, tradução nossa). Além disso, a redatora-chefe da edição, Carine Roitfeld, aponta para Buenos Aires como a "vertiginosa capital- 
sofrimento, de ditaduras em colisão e crises, da qual uma das consequências mais surpreendentes é uma obstinação para manter a todo custo a cabeça para cima" (ROITFELD, 2006a, p.72). Impulsionada portanto por certa obsessão em mostrar a imagem do "Outro vivendo ao lado do Eu", a revista se lança neste terceiro momento do editorial em um clima evocador de sofrimento, resultado de uma mistura apropriada de excesso, de paixão, de fantasia e de ingenuidade [naïveté].

Esta espécie de sensibilidade do excesso - evidenciada aliás como uma característica latina e associada à imagem da Argentina nesta edição - vem de encontro com a arte de "vanguarda" produzida por Vogue em alguns editoriais, estabelecendo um forte diálogo conceitual e artístico com o universo do luxo pelo viés da moda contemporânea. Nesse sentido, pode-se dizer que a produção desta imagem está a meio caminho do estilo camp, atitude estética voltada para o artifício e o exagero, bem comentada na década de 1960 pela ensaísta e romancista norte-americana Susan Sontag. Ela afirma que este estilo é "uma forma de provar, de encontrar seu prazer sem se embaraçar com julgamento de valor" (SONTAG, 2010, p. 327, tradução nossa), sendo o cinismo e a malícia puros artifícios.

O imaginário francês sobre o vertiginoso sofrimento argentino pretende ser menos sério e mais prazeroso nesta encenação do "teatro da moda", tirando vantagem da "perpétua tensão entre a estética e a moral" (SONTAG, 2010, p. 322). À esquerda o "Eu-narrador", incarnando o corpo [branco] da moda pela loira Boscono, se mostra mais indulgente diante do ferimento do Outro, pois ele é ainda o "Outro do mesmo" - trata-se portanto de uma dupla indulgência. Ferida ainda aberta, traumatismo não digerido, a mão da modelo sobre o ventre faz parte deste processo simbólico de representação do Outro; o "Eu-narrador" tem necessidade de seu "Outro" para aprender a melhor se 
(re)conhecer - seja para lembrar o trauma, sonhar de uma forma diferente ou apenas conviver mais à vontade com a "má consciência europeia a respeito do terceiro-mundo" (SEGURA, 2005, p. 147, tradução nossa).

Talvez seja justamente no coração desta tensão que a cultura olhada [regardée] experimenta tal condição ambígua segundo a memória de sua própria dor: as duas muletas mantidas próximas ao corpo e os pés parcialmente suspensos se aproximam das sequelas físicas encontradas nas duas grandes guerras mundiais - e não necessariamente no período da mais dura ditadura militar e civil vivida entre os anos 1976 e 1983 pelos argentinos, cujas consequências mais graves envolveram pessoas desaparecidas, torturas, desvios de bens e reféns.

Se a palidez da deficiência simboliza um diálogo sério e monocromático, o camp nesse caso faz lembrar que a experiência do sofrimento em Vogue pode ser vista sob o ângulo estético. Na imagem, a França é valorizada enquanto espelho de sua própria influência histórica sobre a Argentina do século XXI e de sua tradição cultural nos domínios da costura e da decoração, ditos haut de gamme: a manequim usa um vestido preto em tafetá de seda assinado pela marca Chanel, casa tradicional francesa de moda de luxo de estilo clássico e intemporal; usa sandálias em couro metalizado de Balenciaga por Nicolas Ghesquière (criador francês de estilo vanguardista) e bracelete "cabeça de morte" de prata assinado por Tom Binns (criador irlandês da alta joalheria, com estilo original).

Há ainda nesta imagem um outro signo datado, que faz referência ao universo europeu, mais precisamente ao mobiliário francês: poltrona de madeira com tachas de metal e revestida da estampa toile de Jouy - presente também na parede. Este tecido indiano de algodão era fabricado pela manufatura de Christophe-Philippe Oberkampf em 1760, 
próxima da Corte de Versailles; sobre a estrutura eram representadas cenas bucólicas ou mitológicas de personagens, que se tornaram certificadas como provenientes daquele lugar (appelation française). Nota-se neste sonho camp uma espécie de mitificação do tempo histórico e eventualmente narrativo.

Em relação ao espaço estrangeiro, os distintos planos do campo atribuídos a cada lado das páginas revelam de imediato um diálogo diferencialista de reconhecimento do Outro, apesar da aparente vontade da revista em dar visibilidade aos dois países - projetando-se em torno da philia.

Conforme Pageaux (2007), o processo de (re)organização do espaço estrangeiro é constantemente marcado pela oposição "Eu" vs "Outro", mais precisamente nessas duas imagens: a cidade (casa, hotel) vs campo (pampa), proximidade (familiar, colorido) vs distância (desconhecido, preto e branco), dentro (cultura europeia) vs fora (natureza sul-americana). Estes confirmam o fato de que toda cultura se define também em oposição às outras. Aliás, os laços entre a identidade que olha [regardante] e a alteridade olhada [regardée] são sempre complexos, como bem advertiu Mauricio Segura (2005).

Guiada pela "tensão entre estética e moral" (SONTAG, 2010, p. 322, tradução nossa), Vogue opera à direita um deslizamento do sentido de ferimento, tornando-o erotizado. O sofrimento parece mudar de polaridade, pois o duplo está igualmente associado ao sujeito da morte e ao desejo de sobrevivência, retomando Cavalheiro e Fonseca (2011) sobre o conto de Borges, L'Autre, le Même.

Assim, o "Eu-narrador", sempre duplicado no "Outro do mesmo", experimenta uma ambivalência simbólica criada pelo interesse apaixonado e pelo terror diante da alteridade: de um lado, iria buscar pela proteção de uma destruição 
completa - que aliás não poderia mais ser assegurada pela aparição durável de uma França enquanto "denominador comum político e cultural federativo de boa parte das elites latino-americanas sensíveis a este universalismo francês", como acreditava Emmanuel Todd (1983 apud ROLLAND, 2000, p. 86, tradução nossa); e, de outro, o "Eu-narrador" experimentaria a ameaça de morte por seu duplo, percebido como "mensageiro assustador do desejo" - em cena graças ao erotismo. Fazendo referência a Georges Bataille, para quem a vida e a liberdade são inseparáveis da morte, MarieChristine Lala escreveu:

Desde o medo e o terror vizinhos da obscenidade, da desesperança e da embriaguez, aos limites do esgotamento e do soluço onde não sabemos se iremos rir ou chorar, quando o charme da morte e o da nudez se igualam, é de repente a rajada - com a indiferença e a paixão do rir em conjunto (LALA, 1985, p. 71, tradução nossa).

De fato, para Bataille (1957 apud LIPPI, 2008, tradução nossa), o erotismo é essencialmente o "domínio da violência, da violação", visto que ele é a experiência de um desejo ilimitado até a morte, do Outro ou de si. A encenação erotizada de Vogue é o "negativo" da violência: passa pela violência contida, pela retenção de energia, única via por onde se pode guiar a crise de identidade, segundo Lala (1985). Se trataria afinal de uma identidade francesa "machucada" ? Ou de uma alteridade latino-americana "exótica" e "desprovida" ?

A sociedade argentina do início do século XX era uma sociedade rural sui generis, pois "muitos camponeses foram autênticos pioneiros dotados da mesma mentalidade de compra e energética de seus irmãos de outros países" (BETHELL, 1992 p. 75). Certos símbolos de força desmedida e liberdade na cultura rural argentina (cavalos, terra, árvores da região dos pampas) são confrontados diretamente com o 
fechamento e mesmo o aprisionamento dos corpos, que ganham eles próprios a potência simbólica vertiginosa.

No momento em que o "Eu-narrador" vai em direção ao imensurável, segue em direção ao Outro - ou à perda, no sentido atribuído ao erotismo por Bataille (LIPPI, 2008). Os gestos dos personagens passam por uma "autêntica experiência física" (ROITFELD, 2006a, p.72, tradução nossa), com os braços presos em cercas de arame farpado: as duas jovens manequins jogam com o vencido, o exausto, o sem esperança e o corajoso, o invencível, o provocador. Ambas liberam o que Vogue Paris captou da Argentina: "o sexappeal, o mistério e as contradições desta capital tentada que fascina" (Vogue Paris, 2006, p. 210, tradução nossa).

Em meio ao campo, Mariacarla Boscono usa um vestido em crepe de seda com um decote tubular e detalhes em silicone; Patricia Schmid usa um vestido recortado em gabardine de algodão moldado ao corpo. As duas peças sao assinadas por Hussein Chalayan, criador chipriota e britânico de estilo experimental e conceitual. Para que "o charme da morte e da nudez se igualem", Vogue escolheu justamente um criador que se interroga sobre o mundo, a política, a guerra e a religião, em torno de temas como desenraizamento e identidade, isolamento e opressão.

Se o prazer implica também em certo desaparecimento (LIPPI, 2008), talvez uma perda seja desvelada simbolicamente pelas ambiguidades do desejo e dos corpos em Vogue Paris neste terceiro momento de representação sobre a Argentina. Finalmente, as imagens analisadas demonstraram o quanto Vogue Paris procurou desenvolver determinados processos de avaliação e de reinterpretação da Argentina, de forma a encenar o Outro vivendo ao lado do "Eu-narrador". 


\section{REFERÊNCIAS}

BEST, Kate Nelson. Fashioning the figure of French Creativity: a historical perspective on the political function of French Fashion Discourse. Web Journal of Media French Studies, 2008.

http://www.middlebrowcanada.org/Bibliography.aspx\#tastec onsumptionfashionadvertising. Acesso em: 22 jan. 2015.

BETHELL, Leslie. Argentina en 1914: las pampas, el interior, Buenos Aires. In: BETHELL, L. (org.). Historia de América latina. 10. América del Sur, c. 1870-1930. Barcelona: Editorial Crítica, 1992. pp. 67-88.

CAVALHEIRO, Juciane; FONSECA, Rosa Maria Tavares. O duplo em Borges: análise dos contos "O Outro", "O sul", "O inverossímel impostor Tom Castro" e "O morto". Anuário de Literatura, Florianópolis, v. 16, n. 1, p. 154-170, june 2011. ISSN 2175-7917.

FRIERA, Silvina. O mito é antipolítico, pois a política é discutível. Entrevista com o antropólogo Alejandro Grimson. Instituto Humanitas Unisinos, 21 de novembro de 2012. Disponível em: http://www.ihu.unisinos.br/noticias/515719o-mito-e-antipolitico-pois-a-politica-e-discutivel-entrevistacom-o-antropologo-alejandro-grimson. Acesso em 10 jan. 2015.

LALA, Marie-Christine. La pensée de Georges Bataille et I'oeuvre de la mort. In: Littérature, n. 58, 1985. Le savoir de l'écrit. Pp. 60-74.

LEITÃO, Débora Krischke. Brasil à moda da casa: imagens da nação na moda brasileira contemporânea. Tese de Doutorado (Programa de Pós-Graduação em Antropologia Social) - Instituto de Filosofia e Ciências Humanas Universidade Federal do Rio Grande do Sul: Porto Alegre, 2007. 373 p.

LIPPI, Silvia. «Introduction », Transgressions, Toulouse, ERES , «Point Hors Ligne», 2008, 264 pages. Disponível em: www.cairn.info/transgressions--9782749209753-page-

11.htm. Acesso em 10 fev. 2015

PAGEAUX, Daniel-Henri. Littératures et cultures en dialogue. Paris: L'Harmattan, 2007.

PAULS, Alan. Ville aux trésors. Vogue Paris. Paris: Les Publications Condé Nast S. A., n. 864, février 2006. p. 210211

POIBLANC, Ludivine. Evita. Vogue Paris. . Paris: Les

Publications Condé Nast S. A., n. 864, février 2006. p. 83-88 
RACHLINE, Sonia. Cinéma vérités. Vogue Paris. Paris: Les Publications Condé Nast S. A., n. 864, février 2006b. p. 260265

ROITFELD, Carine. Le point de vue de Vogue. Vogue Paris. Paris: Les Publications Condé Nast S. A., n. 864, février 2006a. p. 72

- Tango des passions. Vogue Paris. Paris: Les Publications Condé Nast S. A., n. 864, février 2006b. p. 182203

ROLLAND, Denis. La crise du modèle français. Marianne et I'Amérique latine: culture, politique et identité. Rennes, Presses Universitaires de Rennes, 2000.

L'Amérique latine et la France: acteurs et réseaux d'une relation culturelle. Rennes: Presses Universitaires de Rennes, 2011.

SEGURA, Mauricio. La faucille et le condor: le discours français sur l'Amérique latine, 1950-1985. Montréal: Les Presses de I'Université de Montréal, 2005.

SONTAG, Susan. L'oeuvre parle (Oeuvres completes, vol. 5). Paris, Christian Bourgois, coll. "Titres", 2010.

VOGUE PARIS. Paris: Les Publications Condé Nast S.A., n. 864, février 2006. 